\title{
Nephrolepis exaltata - Hibiscus rosa-sinensis combination herbal mask decreases levels of reactive oxygen species in nasal wash
}

\author{
Awal Prasetyo*, Resti Ariani**, Arlita Leniseptaria Antari***, Udadi Sadhana ${ }^{\dagger}$, \\ Ika Pawitra Miranti ${ }^{\dagger}$, and Tri Nur Kristina***
}

\begin{abstract}
*Department of Biomedical Science, Faculty of Medicine, Diponegoro University, Semarang, Indonesia **Blood Bank Technology, Bina Trada Polytechnic (POLBITRADA),

Semarang, Indonesia

***Department of Microbiology, Faculty of Medicine, Diponegoro University/Kariadi Hospital,

\section{BACKGROUND}

Poor air and mask quality in the work environment increase the risks of inflammation, reactive oxygen species (ROS) production, ongoing oxidative stress, and superoxide dismutase 3 (SOD3) levels in the airways. The study aimed to investigate the effect of the Nephrolepis exaltata - Hibiscus rosa-sinensis (NE-HRS) combination herbal mask on the airways, as measured by ROS and SOD3 levels in the nasal wash of textile industry workers.
\end{abstract}

Semarang, Indonesia

$\dagger$ Department of Anatomic Pathology, Faculty of Medicine, Diponegoro University/Kariadi Hospital,

Semarang, Indonesia

\section{Correspondence:}

Awal Prasetyo

Department of Biomedical Science,

Faculty of Medicine, Diponegoro

University, Semarang, Indonesia

email: awalpras@fk.undip.ac.id,

awalpras@yahoo.com

mobile phone: $+62-8122810954$

ORCID ID : 0000-0002-1187-1245

Date of first submission, May 14, 2020

Date of final revised submission,

November 12, 2020

Date of acceptance, November 16, 2020

This open access article is distributed under a Creative Commons AttributionNon Commercial-Share Alike 4.0 International License

\section{METHODS}

This was a pre- and post-test randomized controlled trial, consisting of 30 subjects with $\geq 5$-year working time, conducted for eight weeks and monitored every ten days. Subjects were randomized into 3 groups, regular surgical mask group $(n=10)$, NE-HRS combination herbal mask group $(n=10)$ and factory mask group $(n=10)$. SOD3 and ROS levels were determined using ELISA. Data were analyzed with One-way ANOVA and multiple comparison tests.

\section{RESULTS}

ROS levels decreased significantly in all groups $(\mathrm{p}=0.004)$. Regular surgical masks decreased ROS levels by $67.90 \pm 50.66 \mathrm{pg} / \mathrm{mL}$, NE-HRS combination herbal masks by $49.91 \pm 45.06 \mathrm{pg} / \mathrm{mL}$, and factory masks by $193.96 \pm 128.36$ $\mathrm{pg} / \mathrm{ml}$. SOD3 levels also decreased but not significantly $(\mathrm{p}=0.053)$. Differences in ROS levels between surgical mask and NE-HRS combination herbal mask was not significant $(\mathrm{p}=0.796)$.

\section{CONCLUSION}

Herbal masks laminated with NE-HRS combination significantly reduced ROS levels among textile industry workers. NE-HRS combination herbal masks have a similar protective effect to the regular surgical mask.

Keywords: Herbal mask, ROS, SOD3, textile industry workers 


\section{INTRODUCTION}

Poor air condition due to exposure to pollutants can cause serious respiratory problems, especially if the pollutants are reactive chemicals that easily initiate inflammation. The body will respond continuously with a series of dramatic biological processes if the pollutants are inhaled continuously for a long period of time. The initial risk can result from excessive mucus production, damage to the protective epithelium of the respiratory tract, and malignancy. ${ }^{(1,2)}$

Early prevention of diseases of the respiratory tract consists in the use of good quality masks. Thus, the chance of acute and chronic inflammation in the respiratory tract can be reduced and the inflammatory response including the secretion of pro-inflammatory cytokines, chemokine up-regulation, and other complex transduction signals that lead to proliferation and excessive cell activation can be controlled. ${ }^{(3)}$ Another important focus that attracts attention is the changing balance of reactive oxygen species (ROS) and superoxide dismutase 3 (SOD3) in the body when inflammation occurs. Inhaled air pollutants deposited in the respiratory tract cause chemical reactions in the body that produce $\mathrm{ROS}\left(\mathrm{OH}^{-}\right.$, $\mathrm{O}_{2}^{-}, \mathrm{HO}_{2}$, and $\mathrm{H}_{2} \mathrm{O}_{2}$ ) in the respiratory tract. Excessive production of ROS results in oxidative stress which can injure cells and tissues. ${ }^{(4)}$

Masks with Nephrolepis exaltata (NE) herbal laminate are reported to be able to protect the respiratory tract better. The use of NE herbal masks significantly inhibits the production of the pro-inflammatory cytokine tumor necrosis factor $\alpha(\mathrm{TNF}-\alpha)$ in tests of a limited population of textile industry workers exposed to reactive chemicals. Similar studies also show that NE herbal masks work actively in suppressing high free ROS and result in decreased superoxide dismutase 3 SOD3, leading to an oxidant-antioxidant imbalance. ${ }^{(5)} \mathrm{An}$ experimental study showed that the NE herbal mask is better in increasing IgA and improving the pulmonary function in textile workers compared to the regular mask. ${ }^{(6)}$
The ethanol extract of Hibiscus rosasinensis (HRS) contains flavonoids, saponins and steroids and might be responsible for significant inhibition of inflammation, which may involve inhibition of prostaglandins, ${ }^{(7)}$ as well as blocking of the oxidative stress.

Our previous study on different subjects recommended the further study of the potency of the NE herbal mask on the sinonasal cellular immune system ${ }^{(6)}$ and the present study added the measurement variables to prove the effect of the NE-HRS combination herbal mask on sinonasal oxidative stress. This study was expected to prove the effectiveness of the NEHRS combination herbal mask in decreasing the levels of ROS and SOD3 in textile dyeing factory workers.

\section{METHODS}

\section{Research design}

This study used a non-blinded experimental design with pre-and post-test randomized controlled trial and was conducted in PT. APAC Inti Corpora, Bawen, Semarang, between September-October 2019.

\section{Research subjects}

The study recruited 36 subjects that fulfilled the inclusion criteria, but only 30 subjects were included ( 2 subjects not meeting the inclusion criteria and 4 subjects declining to participate). The study sample consisted of employees of a garment factory in Bawen, Semarang, who had been exposed to occupational chemicals in the dyeing process section. In total, 30 employees were selected based on the inclusion criteria i.e., 25-50 years old, healthy, and willing to be a research subject; and the exclusion criteria i.e., having a history of alcohol consumption, smoking, liver disease, autoimmune disease, cancer, pulmonary and heart disease and/or being pregnant; . The sample was not similar to that of our previous study. ${ }^{(6)}$

The sample comprised 30 male textile factory workers, 25-50 years old, and working 
in the dyeing and sizing areas. The sample size determination was based on the total number of male workers in the dangerously polluted area of the factory (dyeing area). The inclusion criteria also included subjects having complaints of mucus or watery discharge out of the nose and a working time (in a textile factory) of $\geq 5$ years. The allocation of the groups was done using the randomized block method with block size $=6$ (using randomly generated numbers). The subjects were randomized into the groups wearing i) regular medical/surgical masks $(n=10)$, ii) NE-HRS combination herbal masks (regular medical/surgical masks that were laminated with NE and HRS extracts) $(n=10)$ and iii) factory masks (single-ply cloth masks) $(n=10)$. To the subjects it was explained how to use the masks correctly. The researchers gave the masks to the supervisor of the subjects every 10 days, then the supervisor distributed the masks to the subjects and ensured the compliance of mask wearing. The masks were used in the work area and were replaced daily for 8 weeks. The duration of wearing masks per day was around 6-7 hours on work days. Compliance in using the masks was ensured by daily supervision using monitoring cards and follow-up by the researchers was done every 10 days to evaluate the usage of masks and the health condition of the research subjects. After 8 weeks, a second measurement of ROS and SOD3 was done. The present study determined the protective effect of the masks from the ROS and SOD3 levels, but did not report on the evaluation of the usage of masks and health conditions of the subjects.

\section{Preparation of plant extracts and herbal masks}

The process of making extracts of Nephrolepis exaltata and Hibiscus rosasinensis was carried out at the Laboratory of Science and Mathematics, Diponegoro University, Semarang, while the herbal masks as well as the regular surgical masks were made by CV. Beauty Kasatama, Surabaya. The herbal masks were prepared by a lamination technique (three-ply surgical masks were laminated with NE-HRS extracts) to maximize the quality and comfort of the mask design. The single-ply cloth masks were produced by the factory itself. Details of the procedures are as specified in Indonesian simple patents nos. S00201909409 and S00201909412, both published on January 21, 2020.

\section{Laboratory analysis}

For examination of SOD3 and ROS levels nasal wash samples were used. Subjects were instructed to sit with the head extended at $45^{\circ}$, then to take a deep breath and hold their breath. A syringe filled with $5 \mathrm{ml}$ of isotonic solution at $37^{\circ} \mathrm{C}$ was inserted into one nostril (with the other nostril closed). The subjects were to hold their position for a few seconds, then look down and slowly drain the liquid into a container. The procedure was to be repeated for other nostril and the whole procedure done in duplicate. All nasal wash fluid samples were stored at $4^{\circ} \mathrm{C}$. Each sample was processed for testing by the ELISA method. The ELISA test for SOD3 levels used human SOD3 (Extracellular superoxide dismutase [Cu-Zn]) ELISA kit) while for ROS levels the human reactive oxygen species (ROS) ELISA kit was used.

\section{Statistical analysis}

The data were analyzed with SPSS for Windows version 25. Primary data on SOD3 and ROS were analyzed by the Shapiro-Wilk test to determine the data distribution, which turned out to be normal. The One-way ANOVA test was used to analyze the data. If significant the analysis was continued using multiple comparison tests.

\section{Ethical clearance}

This study was approved by the health research ethics commission of the Faculty of Medicine, UNDIP and Dr. Kariadi Hospital, Semarang, under No. 194/EC/KEPK/FK UNDIP/V/2019. 


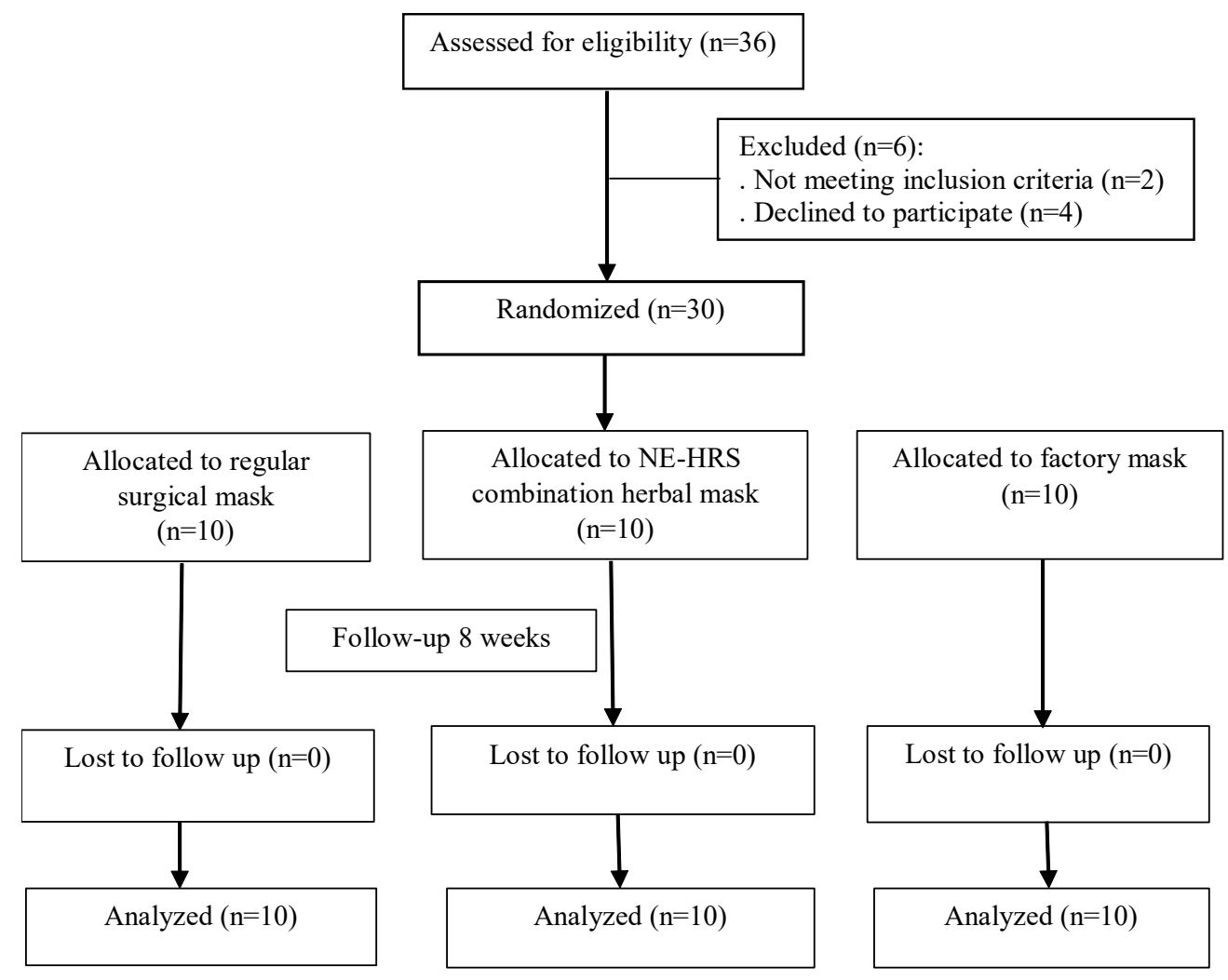

Figure 1. Flow diagram of the participants

\section{RESULTS}

The study included 36 subjects that fulfilled the inclusion criteria, but only 30 subjects were included ( 2 subjects not meeting the inclusion criteria and 4 subjects declining to participate). During the study period, 30 male subjects were randomized into three groups. Ten subjects were in the regular surgical mask group, 10 subjects in the NE-HRS combination herbal mask group and 10 subjects in the factory mask group. They were followed-up for 8 weeks (Figure 1).

At base line, there were no significant differences in age, work duration, and SOD3 level, respectively, between the three groups $(\mathrm{p}=0.318$; $\mathrm{p}=0.626 ; \mathrm{p}=0.29$ ), but there was a significant difference in ROS level between the three groups (Table 1). This means that the randomization process was unable to equally distribute all variables among the three groups. After exposure for 8 weeks, it appears that ROS showed significant results (Table 2).

The ROS levels between groups were significantly different, in that the pre- and posttest multiple comparison showed significant results between regular surgical mask, NE-HRS combination herbal mask, and factory mask $(\mathrm{p}<0.05)$, but no significant difference between regular surgical mask and NE-HRS combination herbal mask (Table 3). This indicates that the

Table 1. Demographic characteristics, ROS and SOD3 by treatment group at base-line

\begin{tabular}{lcccc}
\hline \multicolumn{1}{c}{ Variables } & $\begin{array}{c}\text { Regular surgical } \\
\text { mask }(\mathbf{n}=\mathbf{1 0})\end{array}$ & $\begin{array}{c}\text { NE-HRS herbal } \\
\text { mask }(\mathbf{n}=\mathbf{1 0})\end{array}$ & $\begin{array}{c}\text { Factory mask } \\
(\mathbf{n}=\mathbf{1 0})\end{array}$ & p value \\
\hline Age (yrs) & $38.25 \pm 6.76$ & $38.13 \pm 7.81$ & $41.63 \pm 8.57$ & 0.318 \\
Length of work (yrs) & $15.00 \pm 9.74$ & $16.25 \pm 9.74$ & $19.25 \pm 7.65$ & 0.626 \\
ROS (pg /mL) & $147.00 \pm 79.89$ & $134.66 \pm 73.33$ & $329.44 \pm 122.28$ & 0.001 \\
SOD3 (ng /mL) & $4.02 \pm 2.18$ & $4.26 \pm 1.62$ & $3.27 \pm 0.96$ & 0.239 \\
\hline
\end{tabular}

Note: ROS: reactive oxygen species; SOD3: superoxide dismutase 3 
Table 2. ROS and SOD3 levels after 8 weeks of exposure, by treatment group

\begin{tabular}{lcccc} 
Characteristics & $\begin{array}{c}\text { Regular surgical mask } \\
(\mathbf{n}=\mathbf{1 0})\end{array}$ & $\begin{array}{c}\text { NE-HRS herbal } \\
\text { mask }(\mathbf{n}=\mathbf{1 0})\end{array}$ & $\begin{array}{c}\text { Factory mask } \\
(\mathbf{n = 1 0})\end{array}$ & p value \\
\hline ROS $(\mathrm{pg} / \mathrm{mL})$ & $79.10 \pm 32.89$ & $84.76 \pm 40.99$ & $135.48 \pm 20.98$ & $0.004^{*}$ \\
SOD3 $(\mathrm{ng} / \mathrm{mL})$ & $0.81 \pm 0.12$ & $0.67 \pm 0.10$ & $0.77 \pm 0.12$ & 0.053 \\
\hline
\end{tabular}

Note: ROS: reactive oxygen species; SOD3: superoxide dismutase 3

protective effect of the NE-HRS combination herbal mask was similar to that of the regular surgical mask.

\section{DISCUSSION}

The study showed the effectiveness of the NE-HRS combination herbal mask in reducing the levels of ROS significantly, but failed to prove a significant decreasing effect on SOD3 level. All treatment groups showed a decrease in SOD3 levels with different protective powers. Statistically, SOD3 levels after wearing the masks did not show any significant differences, although the greatest decline was found in the herbal mask group.

It has been known that volatile organic compound (VOC), azo dyes, anthraquinone derivatives, $\mathrm{CH} 3 \mathrm{COOH}, \mathrm{HCOOH}, \mathrm{NaOH}$, $\mathrm{NaHS}$, and formaldehyde are some of the ingredients that are often involved in the coloring process in the textile industry. The heating process at high temperatures $\left(60^{\circ}-79^{\circ} \mathrm{C}\right)$ to strengthen covalent bonds with fabric fibers causes the reactive dyes to evaporate and emit a sharp odor. ${ }^{(8)}$ The fumes released into the air during the coloring process contains $\mathrm{H}_{2} \mathrm{~S}$ and $\mathrm{NO}$ which are easily inhaled by workers and become inflammatory agents in the respiratory tract. ${ }^{(9)}$ Microscopic observations show that airway inflammation due to exposure to formaldehyde $\left(\mathrm{H}_{2} \mathrm{CO}\right)$ and VOC complexes with NOx in the air is characterized by erosion of airway epithelial cells, goblet cell metaplasia and hyperplasia of flat epithelial cells. ${ }^{(10,11)}$

Inhaled pollutants deposited in the respiratory tract cause inflammation and chemical reactions in the body and produce reactive oxygen species ( $\mathrm{ROS}, \mathrm{OH}^{-}, \mathrm{O}_{2}^{-}, \mathrm{HO}_{2}$, and $\mathrm{H}_{2} \mathrm{O}_{2}$ ) that cover the respiratory tract. Some studies have shown that excessive ROS production in oxidative stress can injure cells and tissues in the respiratory tract. This condition then disturbs the oxidantantioxidant balance in the body. $N$. exaltata extract was chosen as a coating on herbal masks because of its strong antioxidant content, inhibition of human bronchial epithelial carcinoma (BEAS2B) cells and counteracting of oxidative stress due to inhaled VOCs. ${ }^{(12)}$ In this study, NE herbs were enriched with the addition of HRS to maximize its protective function in suppressing inflammation and oxidative stress due to an imbalance between ROS and antioxidants. ${ }^{(13-15)}$

The analysis of ROS levels of the workers showed that all three types of masks used were protective. All study groups (regular, herbal mask or factory mask groups) were capable of reducing workers' ROS levels significantly. At base-line, the distribution of all variables between groups was homogenous, except for the ROS level. After 8 weeks exposure the factory mask group surprisingly showed an extreme decrease in ROS level. Theoretically, the reactive oxygen species levels in the factory mask group should have been the highest compared to the other two groups. This is because in factory masks, the filter

Table 3. Multiple comparison of pre- and post-test of ROS levels

\begin{tabular}{lcc}
\multicolumn{1}{c}{ Treatment groups } & Mean differences & p value \\
\hline Regular surgical mask NE-HRS combination herbal mask & $12.34 \pm 47.18$ & 0.796 \\
Factory mask & $-182.44 \pm 47.18$ & 0.001 \\
NE-HRS combination herbal mask Factory mask & $-194.78 \pm 47.18$ & 0.000 \\
\hline
\end{tabular}

The mean difference was significant at the 0.05 level 
density used tends to be more lax and more likely to pass inhaled pollutants into the respiratory tract. Exogenous agents (reactive chemicals, ozone, nitrogen dioxide, cigarette smoke, pollutants, radiation, drugs, nutritional intake) and endogenous agents (inflammation, organelle damage, peroxisomes, mitochondria and cell metabolism) are the components that are involved in causing the levels of ROS in the body. ${ }^{(14)}$

The mechanisms of interaction of pollutants and ROS components with the body structure are complex, but one hypothesis is the involvement of reduction-oxidation (redox) reaction cycle in the epithelial lining of the respiratory tract. ${ }^{(4)}$ This process is initiated by the transfer of electrons from antioxidants to quinone transition metal ions to form reduced metal ions or semiquinones. This process is further rearranged by the reaction with $\mathrm{O}_{2}$ to form the oxygen free radical which is then converted to $\mathrm{H}_{2} \mathrm{O}_{2}$ which is the center of the cycle of radical reactions and oxidative stress in the respiratory tract. ${ }^{(15)}$ Basically, oxidant production is neutralized by several antioxidants through cellular mechanisms in the respiratory tract. Intracellular antioxidants in the respiratory tract include catalase, SOD, and glutathione, formed by the enzymes $\gamma$-glutamyl cysteine synthetase and glutathione synthetase.

The SOD3 test results of the workers after using a mask showed better data (because the improving of SOD3 levels) and these indicated protective functions; however, the differences among groups were not significant. All treatment groups showed a decrease in SOD3 levels with a different protective power. Statistically, the difference in the SOD3 levels after wearing the masks did not show any significant difference, but the greatest decline was found in the herbal mask group. One possible reason for this finding is that the herbal mask gives double protection to the factory workers, as antioxidant as well as antiinflammatory agent, to prevent pulmonary edema. ${ }^{(16)}$

This study found that using masks prevented the decrease in the level of SOD3 and the increase of ROS, although the results were not significant.
This is in line with a previous study, that found that using a mask protected the respiratory system from harmfull pollutants. ${ }^{(17)}$ These results also represent the concept of an oxidantantioxidant balance, where good health status allows one to be able to adapt to external stimuli and maintain the immune system, so the ups and downs of SOD3 levels are closely related to the deposition of high and low ROS in the body. ${ }^{(18)}$ This result was also in line with a previous study stating that SOD3 levels in the extracellular matrix decreased with the alveolar injury condition of animals which gradually improved. ${ }^{(19)}$

Previously, observations of the level of the cytokine TNF- $\alpha$ as inflammatory marker showed a significant decrease in levels after routine wearing of masks by the workers. ${ }^{(20)}$ This condition turned out to be synergistic with SOD3's position as an antioxidant agent that plays a role in reducing the migration of inflammatory cells with regulation of adhesion molecules such as tumor necrosis factor (TNF)- $\alpha$, interleukin (IL)$1 \alpha$, IL6, macrophage inflammatory protein (MIP)2, monocyte chemoattractant protein (MCP)-1, vascular adhesion molecule (VCAM), intercellular adhesion molecule (ICAM), Pselectin, and E-selectin in inflammatory tissues. The balance between antioxidants and ROS is also supported by research showing that antioxidant levels increase with increasing ROS levels in the healthy control group. Conversely, antioxidants drop when ROS levels are reduced. This will be different in pathological conditions in which ROS accumulate in many cells and tissues. The addition of exogenous antioxidants to a certain extent actually stimulates the production of higher levels of endogenous antioxidants because it balances excessive ROS levels in the body. ${ }^{(21)}$

Some factors influenced the results of this study, both internal and external factors. The dyeing area was chosen as the location of the study because it involved the greatest number of chemicals in the coloring process. The risk of inhalation of these chemicals is due to the low degree of awareness of the workers who lack discipline in using personal protective 
equipment. In fact, the coloring process takes place at high temperatures and emits strongsmelling hot steam. In addition to the location and discipline of workers, smoking habits, good nutritional intake, age and sex are thought to have participated in influencing ROS and SOD levels throughout the study. Further study is needed about the use of the NE-HRS combination herbal mask in other industries, the prolonged use of the NE-HRS combination herbal mask, and other combinations of herbal mask composition.

The limitation of this study was that the time for data collection could not be equated to all samples, and may have been aûected by the physical and mental conditions of the subjects. The limited population of subjects was also suggested to be another limitation of the study, and may be attributed to differences in the conditions of the work environment. The clinical implication of the study is the importance of wearing a mask, especially in polluted areas, that should become a daily habit. The further studies should be directed to prove the potency of the NE-HRS combination herbal mask on the cellular immune system as well as lung functions in acute exposure, compared to the N95 mask.

\section{CONCLUSION}

This study demonstrated that the NE-HRS combination herbal mask was capable of reducing the ROS levels among industrial textile workers. The protective effect of the NE-HRS combination herbal mask was similar to that of the regular surgical mask.

\section{CONFLICT OF INTEREST}

The authors declare that they have no conûicts of interest concerning this article.

\section{ACKNOWLEDGEMENT}

We thank all laboratory and nursing personnel and the funding agency for this study.

\section{REFERENCES}

1. Watanabe M, Noma H, Kurai J, et al. Effects of short-term exposure to particulate air pollutants on the inflammatory response and respiratory symptoms: a panel study in schoolchildren from rural areas of Japan. Int J Environ Res Public Health 2016;13:983. doi: 10.3390/ijerph13100983.

2. Wang H, Song $\mathrm{L}$, Ju W, et al. The acute airway inflammation induced by $\mathrm{PM}_{25}$ exposure and the treatment of essential oils in Balb/c mice. Sci Rep 2017;7:44256. doi: 10.1038/srep44256.

3. Shakya KM, Noyes A, Kallin R, Peltier RE. Evaluating the efficacy of cloth facemasks in reducing particulate matter exposure. J Expo Sci Environ Epidemiol 2017;27:352-7. doi: 10.1038/ jes.2016.42.

4. Lakey PSJ, Berkemeier T, Tong H, et al. Chemical exposure-response relationship between air pollutants and reactive oxygen species in the human respiratory tract. Sci Rep 2016;6:32916. doi: 10.1038/srep32916.

5. Paramitha NA, Sadhana U, Prasetyo A, Karlowee $\mathrm{V}$. The increasing of interleukin 6 and superoxide dismutase 3 nasal wash in textile industry workers exposed by occupational air pollutant. Indian $\mathrm{J}$ Sci Technol 2020;13:3002-7. doi: 10.17485/IJST/ v13i29.369.

6. Prasetyo A, Rahardja AA, Azzahro AT, et al. Nephrolepis exaltata herbal mask increases nasal IgA levels and pulmonary function in textile factory workers. Adv Prev Med 2019, Article ID 5687135, 7 pages. doi: 10.1155/2019/5687135.

7. Raduan SZ, Abdul Aziz MWH, Roslida AH, et al. Anti-inflammatory effects of Hibiscus rosasintensis $\mathrm{L}$ and Hibiscus rosa-sinensis var alba ethanol extracts. Int J Pharm Pharm Sci 2013;5:75462.

8. Nodoushan MS, Mehrparvar AH, Loukzadeh Z, et a. Evaluation of respiratory system in textiledyeing workers. Med J Islam Repub Iran 2014;28:8.

9. Ozkurt S, Kargi BA, Kavas M, et al. Respiratory symptoms and pulmonary functions of workers employed in Turkish textile dyeing factories. Int $\mathrm{J}$ Environ Res Public Health 2012;1068-76. doi: 10.3390/ijerph9041068.

10. Yorgancilar E, Deveci E, Deveci S. Effects of formaldehyde on respiratory mucosa in rats. Int $\mathrm{J}$ Morphol 2012;30:521-3. http://dx.doi.org/10.4067/ S0717-95022012000200026.

11. Arbex MA, Santos UDP, Martins LC, et al. Air pollution and the respiratory system. J Bras Pneumol 2012;38:643-55. DOI: 10.1590/s180637132012000500015 . 
12. Kfoury M, Borgie M, Verdin A, et al. Essential oil components decrease pulmonary and hepatic cells inflammation induced by air pollution particulate matter. Environ Chem Lett 2016;14:34551.

13. Khristi V, Pathel VH. Therapeutic potential of Hibiscus rosa sinensis: a review. IJND 2016;4:105-23. DOI: 10.17654/ND004020105.

14. Boukhenouna S, Wilson MA, Bahmed K, Kosmider B. Reactive oxygen species in chronic obstructive pulmonary disease. Oxid Med Cell Longev 2018, Article ID 5730395, 9 pages. https:/ /doi.org/10.1155/2018/5730395 1-8.

15. Charrier J, McFall A, Richard-Henderson N, Anastasio C. Hydrogen peroxide formation in a surrogate lung fluid by transmission metals and quinones present in particulate matter. Environ SciTech 2014;48:7010-7.

16. Jiang X-Q, Mei X-D, Feng D. Air pollution and chronic airway diseases: what should people know and do? J Thorac Dis 2016;8:E31-40. DOI: 10.3978/j.issn.2072-1439.2015.11.50.

17. $\mathrm{Hu} \mathrm{L}$, Zachariae ED, Larsen UG, et al. Redox biology the dynamic uptake and release of SOD3 from intracellular stores in macrophages modulates the inflammatory response. Redox Biol 2019; 101268. DOI: 10.1016/j.redox.2019.101268.
18. Poonyagariyagorn HK, Metzger S, Dikeman D, et al. Superoxide dismutase 3 dysregulation in a murine model of neonatal lung injury. Am J Respir Cell Mol Biol 2014 ; 51: 380-90. DOI: 10.1165/ rcmb.2013-0043OC2014;51:380-90.

19. Laurila JP, Laatikainen LE, Castellone MD, Laukkanen MO. SOD3 reduces inflammatory cell migration by regulating adhesion molecule and cytokine expression. PLoS One.2009;4:1-8. https:/ /doi.org/10.1371/journal.pone.0005786.

20. Ariani R, Prasetyo A, Prajoko Y, Suprihati, Sadhana U. Analysis of herbal mask protection effect on tumor necrosis factor- $\alpha$ and interleukin6 levels in the employees of textile industry. In: The $3^{\text {rd }}$ international conference on translational medicine and health science - New direction in management of cardiovascular disease and comprehensive approach to obesity. Semarang; 2019.p.37.

21. Lu X, Wang C, Liu B. The role of $\mathrm{Cu} / \mathrm{Zn}-\mathrm{SOD}$ and $\mathrm{Mn}-\mathrm{SOD}$ in the immune response to oxidative stress and pathogen challenge in the clam Meretrix meretrix. Fish Shellfish Immunol 2015;42:58-65.http://dx.doi.org/10.1016/j.fsi.2014. 10.027 . 